\title{
Foraging strategies of deep-sea fish
}

\author{
J. Mauchline \& J. D. M. Gordon \\ Dunstaffnage Marine Research Laboratory, P.O. Box No. 3, Oban, Argyll PA34 4AD, United Kingdom
}

\begin{abstract}
The structure of the stomach contents of 33 species of fish caught at depths between 400 and $2900 \mathrm{~m}$ in the Rockall Trough is analysed for information on foraging strategies of individual species. One representative (a single) or several representatives (a multiple incidence) of a prey species can occur in stomachs. The contents of stomachs range from 1 to about 200 individual prey items. These items can comprise singles, singles and a multiple incidence, or singles and co-occurring multiple incidences. Relations between the numbers of items occurring as singles or multiple incidences and the total number of items in the stomachs of the different species of fish were examined. An attempt is made to analyse the progressive accumulation of items in stomachs as they become fuller. Results suggest that fish such as the benthopelagic feeding macrourids are exploiting multi-species patches of prey. Four types of general feeding strategies appear to be present among the species. Ten species are primarily opportunistic feeders that occasionally feed repetitively on single prey species. Five species are also opportunistic feeders but lock-on to a single prey species that they exploit repetitively fairly regularly. Four species feed opportunistically on single items but in addition feed repetitively on 1 or more preferred prey species. Six species combine opportunistic and repetitive feeding much more closely to exploit a wide variety of resources. Data on the remaining 8 of the 33 species were not adequate to define their feeding strategies.
\end{abstract}

\section{INTRODUCTION}

Dietary analyses of a wide variety of species of demersal fish have been made in the Rockall Trough by Mauchline \& Gordon $(1980,1983 a, b, 1984 a, b, c)$. The analyses are primarily descriptive, seasonal and ontogenetic aspects being taken into account. The relevant literature is reviewed in these papers. A more analytical approach to the data was used to assess sources of diversity within the diets (Mauchline \& Gordon 1985). The diets are dominated by relatively few components and diversity within a diet is derived directly from the number of minor components occurring.

The type and size of prey consumed is governed to a considerable extent by the functional morphology of the predatory species of fish concerned. The most detailed comparative studies have been made on the macrourid species (Marshall 1965, Okamura 1970, Geistdoerfer 1973, 1978, McLellan 1977). Similar studies on species in other families are less detailed but the results are comparable. The form of the mouth and its position, the structure of the gill rakers, the functional aspects of the swimbladder, and the disposition and form of the fins relative to an active or lethar- gic life style in conjunction with the sensory apparatus for location of prey are all involved. These combined with behavioural and distributional differences between populations of the different species allow exploitation of varying compartments of the resources of prey which themselves exhibit heterogeneous behavioural and distributional patterns.

Behavioural and distributional patterns of potential pelagic prey, especially the ecological importance of patchiness, have received recent attention (Steele 1978). This is the fine-scale (metres to hundreds of metres) and micro-scale $(1 \mathrm{~cm}$ to $1 \mathrm{~m}$ ) of Haury et al. (1978). Such patches may be of single species (Alldredge et al. 1984), but according to Haury \& Wiebe (1982) are more likely to be multi-species in composition. Both these investigations hypothesize the potential ecological importance of such patches in the trophodynamics of oceanic ecosystems.

Horwood \& Cushing (1978), in discussing patchiness in the distributions of prey of pelagic fish, point out that it is metabolically cheaper to feed on patches than on evenly distributed prey. Assuming this to be true then patches within the distributions of prey organisms should be detectable in an examination of the stomach contents of fish. 


\section{GENERAL APPROACH}

The benthopelagic environment of the slope of the Rockall Trough is exploited for food by the demersal fish (Mauchline \& Gordon loc. cit.). It is inhabited by a large variety of organisms normally considered members of the pelagic plankton and micronekton. These organisms are a dominant prey of the assemblages of demersal fish (Marshall \& Merrett 1977, Mauchline \& Gordon loc. cit.).

The stomach contents of a fish are a sample of the potential prey species in the environment around the fish. The efficiency of a pelagic net or benthic sampler in procuring a representative sample of the assemblages at which it is targeted depends on its size, design and structural elements (Angel 1977, Holme \& McIntyre 1984). A fish as a sampler also has selective biases derived from its functional morphology as outlined above. A grab or corer samples a small area or volume (spot sample) while dredges, trawls and the majority of pelagic nets traverse assemblages in more or less straight lines horizontally, obliquely or vertically. A fish can combine all of these but also digress from any one of them on the fine micro-scales of Haury et al. (1978).

In addition, a feeding fish may be caught when it has filled its stomach or at any stage between commencement of feeding and repletion. Some species have up to 200 prey items in a full stomach, others have 3 to 5 , while some stomachs of Synaphobranchus kaupi contain only a single large prey. Identified prey items in a stomach that is nearly empty contribute to a dietary list but provide little information on how a meal, represented by the contents of a full stomach, is constructed. A method is required to examine the progressive acquirement of items between commencement of feeding and repletion. This would define any changing structure within the meal and generate ideas on feeding strategy.

What evidence of exploitation of patches of prey might be found within stomach contents of individual fish? To take the simplest case, a fish exploiting a single species patch of either a benthic or pelagic organism could be expected to have several examples (a multiple incidence or multiple) of that species in its stomach. A fish exploiting a multi-species patch (Haury \& Wiebe 1982) would then be expected to have several examples of several species (co-occurring multiple incidences or co-occurring multiples) in its stomach along with single individuals (singles) of species that occur in small numbers (densities) within the patch.

This is illustrated in Fig. 1 which represents a portion of a multi-species patch of prey containing 1 dominant, 3 sub-dominant and 5 rarer species. The

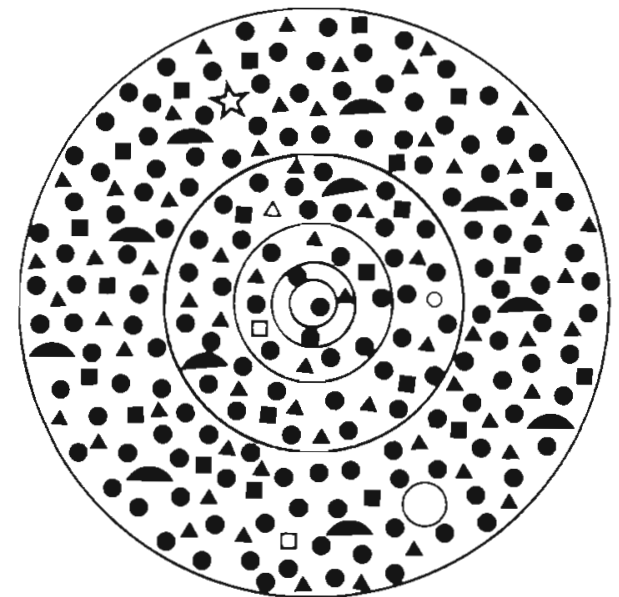

Fig. 1. Diagrammatic illustration of a multispecies patch of zooplankton prey species. The distribution of each species, denoted by different symbols, is random throughout the patch. The concentric circles, each twice the area of the previous, represent successively larger foraging areas of a

fish between commencement of feeding and repletion

species are distributed more or less randomly throughout this portion of the patch. The successively Iarger concentric circles, each twice the area of the previous, represent increasing foraging areas of a fish between commencement of feeding and repletion. Conceptual circular foraging areas are for diagrammatic simplicity. A true foraging area may be an extended tube, its diameter related to that of the fish's mouth, or it can be a zig-zag path. Such regular or irregular areas can be reduced to the form in Fig. 1 for comparative purposes. The resultant stomach contents, as the prey species in each successive area are consumed, are shown in Table 1

Table 1. The resultant stomach contents as a fish progressively consumes all organisms in each successively larger concentric circle superimposed on the multispecies patch in Fig. 1

\begin{tabular}{|c|c|c|c|c|c|c|c|c|c|}
\hline \multirow{2}{*}{$\begin{array}{c}\text { Concentric } \\
\text { circles }\end{array}$} & \multicolumn{9}{|c|}{ Cumulative numbers of each species consumed } \\
\hline & $\bullet$ & $\Delta$ & घ & & $\square$ & $\triangle$ & 0 & & $s_{r}^{2}$ \\
\hline Smallest & 1 & & & & & & & & \\
\hline 2 & 3 & 1 & & & & & & & \\
\hline 3 & 10 & 4 & 1. & & 1 & & & & \\
\hline 4 & 39 & 15 & 5 & 2 & 1 & 1 & 1 & & \\
\hline Largest & 156 & 61 & 22 & 11 & 2 & 1 & 1 & 1 & 1 \\
\hline
\end{tabular}

The stomach contents, therefore, should hypothetically consist first of one or more single representatives of prey species and evolve into a situation where cooccurring multiples are found along with a single representative of additional species (Table 1). This should 
apply not only to exploitation of pelagic multi-species patches but also to those in the epibenthic regime. This paper examines this hypothesis and also the possibility of other modes of feeding being evidenced by structure within stomach contents.

\section{MATERIALS AND METHODS}

The fish were sampled at approximately $250 \mathrm{~m}$ bathymetric intervals between 400 and $2900 \mathrm{~m}$ depth in the Rockall Trough during the period 1975 to 1981

Table 2. The numbers of multiple incidences consisting of different numbers of organisms occurring in stomachs of a variety of demersal species of fish. The numbers of stomachs with and without multiple incidences are also given. Nomenclature of the fish is that of Hureau \& Monod (1979)

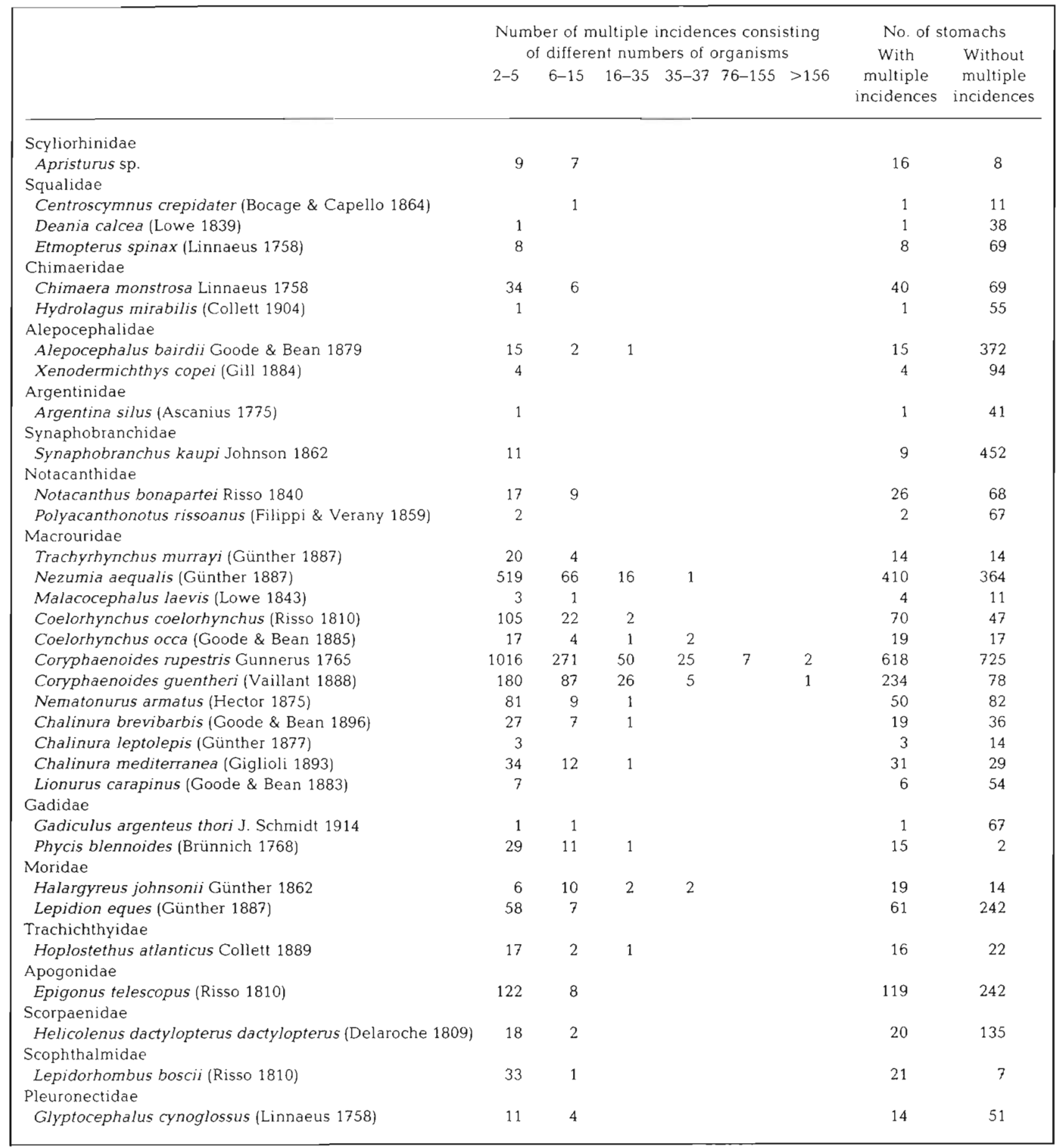


The types of gear used, sampling strategy and an assessment of the accuracy of the samples in representing the fish assemblages investigated are given by Gordon \& Duncan (1985). The dietary samples are representative of the seasons of the year in addition to the majority of species being collected throughout their total bathymetric range

The stomach contents were either preserved on board ship or removed from preserved fish for later examination in the laboratory. All taxa were identified to species level where possible but such identifications are biased in favour of species of calanoid copepods, mysids, euphausiids, decapods and against polychaetes, smaller amphipods, isopods and gelatinous organisms. Small numbers, in a few diets larger numbers, of immature or damaged calanoid copepods were not identified to species. All items were counted in each stomach.

Stomachs of fish within any one sample of fish may be everted, empty or contain food. The number of everted and empty stomachs varies between species and between samples taken at different and the same times of the year. Few correlations exist between the occurrence of everted and empty stomachs and body size or depth of capture of the fish. Consequently, their presence is ignored and only stomachs with food present are discussed in this paper. Stomachs with food present exhibit all degrees of fullness. Partial regurgitation of contents during the process of capturing the fish is frequently suspected to have taken place but cannot be proved. Consequently, partially full stomachs with only a few items of food present may include an unknown number in which contents have been partially regurgitated.

\section{RESULTS}

The stomach contents of 75 species of demersal fish were examined. Contents were present in only 1 to 12 stomachs of each of 40 species, however, and so data on these species may be unreliable and are excluded from this analysis. Approximately $70 \%$ of the items in the diet of the synaphobranchid Histiobranchus bathybius were unidentified fish (Mauchline unpubl.). Similarly, the diet of Antimora rostrata consisted of $70 \%$ unidentified tissues (Mauchline \& Gordon 1984b). Consequently, these 2 species are not included with the remaining 33 species in the following analysis.

\section{Structure within stomach contents}

The occurrence of multiple incidences and single items within the diets of 33 species is shown in Tables
2 and 3. Multiples can range in size from 3 to 100 organisms in any 1 stomach. The proportion of stomachs with and without multiples varies between species (Table 1). The mean number of items in stomachs with multiple incidences is greater than that in stomachs without them (Table 3). This is illustrated for Coelorhynchus coelorhynchus in Fig. 2 which

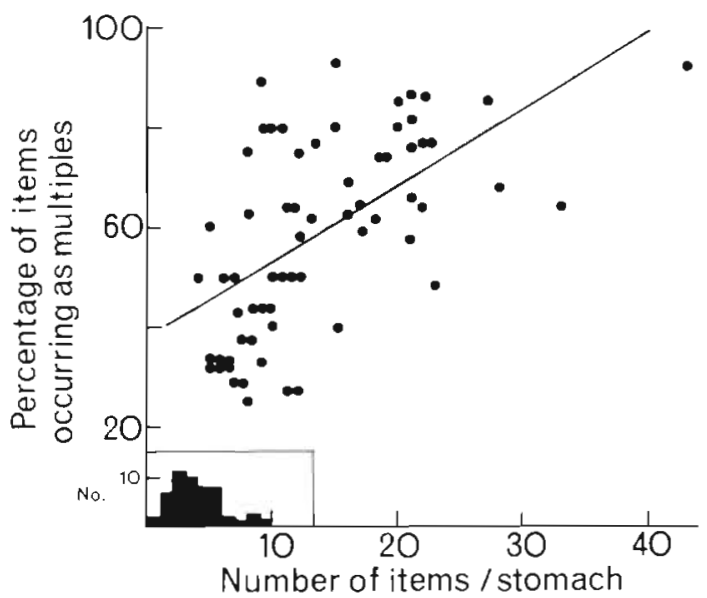

Fig. 2. Coelorbynchus coelorhynchus. The proportion of items occurring as multiples increases as the number of items in the stomach. The equation of the line is: $y=1.53 x+37.82$. The inset histogram shows the numbers of stomachs without multiples present that had different numbers of prey items; none of these stomachs had more than 10 items, whereas stomachs with multiples had 5 to 43 items

shows (inset) that stomachs without multiples have less than 10 items (mean $4.3 \pm 2.0$ ) while those with multiples have 5 to 43 items (mean $13.7 \pm 7.5$ ). The frequency distributions of stomachs with different numbers of prey are skewed towards stomachs with smaller rather than larger numbers so that the calculation of means and standard deviations are not appropriate; only means are shown in Table 3 . The first 2 correlations in Table 4 show that the numbers of co-occurring multiple incidences and the number of items comprising them are directly proportional to the total number of items in the stomachs in most species. The number of single items per stomach, however, is not necessarily related to the total number of items (Table 4) and this will be discussed later.

An assessment of the importance of multiple incidences in the diets can be made by calculating the percentage of the total prey items in the diet that occur exclusively as multiples and the comparable percentage of total items contained in the stomachs with multiple incidences present (Table 3). Comparison of these 2 percentage values shows, first, whether prey occurring as multiple incidences are an important component of the diet; the percentages occurring as multiples range from 2 to $72 \%$. Second, the compari- 
Table 3. Comparison of the quantities of prey items in stomachs with and without multiple incidences

\begin{tabular}{|c|c|c|c|c|}
\hline & \multicolumn{2}{|c|}{$\begin{array}{c}\text { Mean no. of prey items } \\
\text { per stomach }\end{array}$} & \multicolumn{2}{|c|}{$\begin{array}{l}\% \text { of total prey items } \\
\text { occurring }\end{array}$} \\
\hline & $\begin{array}{c}\text { With } \\
\text { multiple } \\
\text { incidences }\end{array}$ & $\begin{array}{l}\text { Without } \\
\text { multiple } \\
\text { incidences }\end{array}$ & $\begin{array}{c}\text { As } \\
\text { multiple } \\
\text { incidences }\end{array}$ & $\begin{array}{c}\text { In stomachs } \\
\text { with multiple } \\
\text { incidences }\end{array}$ \\
\hline Apristurus sp. & 9.1 & 2.9 & 60 & 86 \\
\hline Centroscymus crepidater & 6.0 & 1.2 & 32 & 32 \\
\hline Deania calcea & 3.0 & 1.3 & 6 & 6 \\
\hline Etmopterus spinax & 2.8 & 1.4 & 16 & 19 \\
\hline Chimaera monstrosa & 6.4 & 1.8 & 48 & 67 \\
\hline Hydrolagus mirabilis & 3.0 & 2.0 & 2 & 3 \\
\hline Alepocephalus bairdii & 12.0 & 1.4 & 8 & 27 \\
\hline Xenodermichthys copei & 4.0 & 1.6 & 7 & 10 \\
\hline Argentina silus & 5.0 & 2.0 & 4 & 6 \\
\hline Synaphobranchus kaupi & 2.9 & 1.3 & 5 & 5 \\
\hline Notacanthus bonapartei & 4.9 & 1.3 & 55 & 60 \\
\hline Polyacanthonotus rissoanus & 5.0 & 1.2 & 9 & 11 \\
\hline Trachyrhynchus murrayj & 11.2 & 3.8 & 43 & 75 \\
\hline Nezumia aequalis & 11.6 & 5.3 & 35 & 71 \\
\hline Malacocephalus laevis & 6.0 & 6.7 & 23 & 24 \\
\hline Coelorhynchus coelorhynchus & 13.7 & 4.3 & 31 & 79 \\
\hline Coelorhynchus occa & 14.0 & 2.4 & 61 & 87 \\
\hline Coryphaenoides rupestris & 20.6 & 2.7 & 57 & 86 \\
\hline Coryphaenoides guentheri & 16.1 & 5.0 & 46 & 91 \\
\hline Nematonurus armatus & 15.5 & 3.6 & 28 & 72 \\
\hline Chalinura brevibarbis & 13.7 & 5.8 & 23 & 56 \\
\hline Chalinura leptolepis & 12.3 & 5.9 & 5 & 31 \\
\hline Chalinura mediterranea & 16.0 & 6.5 & 23 & 72 \\
\hline Lionurus carapinus & 7.7 & 3.4 & 7 & 20 \\
\hline Gadiculus argenteus thori & 15.0 & 1.7 & 9 & 12 \\
\hline Phycis blennoides & 17.1 & 4.6 & 52 & $9 ?$ \\
\hline Halargyreus johnsonii & 14.9 & 2.3 & 72 & 87 \\
\hline Lepidion eques & 5.7 & 1.7 & 25 & 46 \\
\hline Hoplostethus atlanticus & 8.6 & 2.6 & 32 & 70 \\
\hline Epigonus telescopus & 5.9 & 2.4 & 30 & 54 \\
\hline Helicolenus dactylopterus dactylopterus & 4.7 & 2.4 & 14 & 22 \\
\hline Lepidorhombus boscii & 6.0 & 3.6 & 45 & 65 \\
\hline Glyptocephalus cynoglossus & 6.2 & 2.5 & 26 & 40 \\
\hline
\end{tabular}

son also shows what proportion of the prey occur in the stomachs with multiples; it is $86 \%$ in Apristurus sp. which means that only $14 \%$ of all items were found in stomachs that only contained single items. These stomachs are usually nearly empty.

Most of the total prey items (>50\%) occur in stomachs with multiple incidences in 17 of the 33 species examined; the proportion of these that occur as multiple incidences in these stomachs, however, ranges from $23 \%$ in Chalinura brevibarbis and $C$. mediterranea to $72 \%$ in Halargyreus johnsonii. In other words, the proportions of single items co-occurring with the multiples varies as inferred from the number of species, in Table 4 , in which the number of items occurring as singles is not correlated with the total number of items in the stomach.

Another list of 12 species in Table 3 has less than $31 \%$ of total prey items occurring as multiples or in stomachs with multiples; multiple incidences in 10 of these species represent less than $10 \%$ of all items recorded in the diet, implying that they are not important.

Samples of most species of fish included all stages between juveniles and adults. Consequently, the number of prey items per stomach in the 33 species was regressed on body length (Table 4) to discover if multiple incidences are more common in stomachs of larger than smaller fish. Positive correlations occur in Chimaera monstrosa and Notacanthus bonapartei and stomachs of larger fish will, therefore, have more items as multiples than those of smaller fish. Negative correlations occur in the other 3 species (Table 4 ) and also in Lionurus carapinus $(\mathrm{r}=-0.402, \mathrm{p}<0.05)$ where larger fish tend to consume fewer but larger prey and will, therefore, have fewer items occurring as multiple incidences. There was no positive correlation in 
Table 4. Species in which prey items occurring in stomachs with multiple incidences represent more than $40 \%$ of the total prey items in the diet (Table 3). The following correlations were attempted for all species but values and significance of $r$ are only given where significant.
Correlation 1 Number of multiple incidences/stomach · Total number of items/stomach
2 Number of items occurring as multiple incidences/stomach: Total number of items/stomach
3 Number of items occurring as singles/stomach Total number of items/stomach
4 Total number of items/stomach Body length of fish

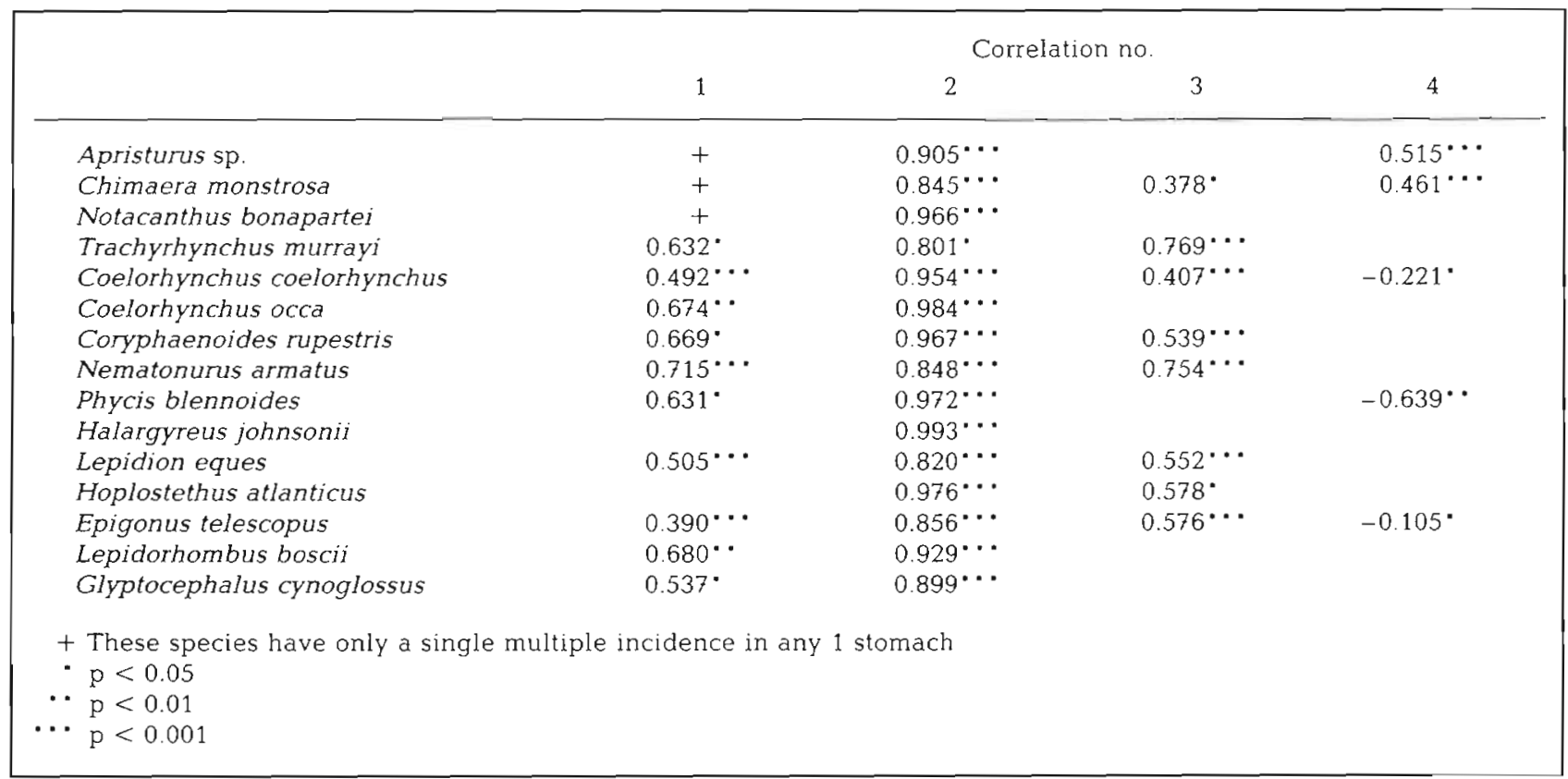

Coryphaenoides rupestris but the mean body lengths of fish with increasing numbers of co-occurring multiples show a trend of increasing size (Table 5).

\section{Prey species that occur as multiple incidences}

Some 230 species of prey were identified in the stomach contents. The apportionment of 186 of these is as follows: calanoid copepods 69 ; amphipods 39 ; mysids 26; euphausiids 5 ; decapod crustaceans 28 ; fish 19. Many of these species are relatively rare among the

Table 5. Coryphaenoides rupestris. Mean body lengths of fish with different numbers of multiple incidences per stomach

\begin{tabular}{crc|}
$\begin{array}{c}\text { No. of } \\
\text { multiples }\end{array}$ & $\begin{array}{c}\text { No. of } \\
\text { fish }\end{array}$ & $\begin{array}{c}\text { Mean total body } \\
\text { length } \pm \text { SD }\end{array}$ \\
\hline 0 & 586 & $44.6 \pm 29.9$ \\
1 & 228 & $42.3 \pm 28.9$ \\
2 & 134 & $46.7 \pm 25.6$ \\
3 & 64 & $51.4 \pm 27.8$ \\
4 & 42 & $45.6 \pm 29.7$ \\
5 & 29 & $51.2 \pm 28.3$ \\
6 & 14 & $60.7 \pm 26.5$ \\
7 & 3 & $69.4 \pm 19.9$ \\
8 & 4 & $80.2 \pm 2.8$ \\
\hline
\end{tabular}

stomach contents and are not found as multiple incidences. Those that are common as multiples are restricted in number, about 30 , and occur in diets of several species of fish (Table 6). A further 10 to 20 species are occasionally recorded as multiples of 2 to 5 individuals. No fish are listed in Table 6 but a few mesopelagic species occur as multiples in stomachs of several predatory species.

The dominance of a relatively few prey species in the stomach contents of the fish fauna of the Rockall Trough is further exemplified in the following analysis. The detailed composition of co-occurring multiples in stomachs of Coryphaenoides rupestris is examined in Tables 7 and 8 . This is the only species examined here that has sufficient numbers of stomachs with 5 or more co-occurring multiple incidences to allow their composition to be examined. The number of times each prey species occurs as the largest, the second largest multiple and so on was determined. The species were then ranked in decreasing order of occurrence within each column (Table 7). The largest multiple was always 1 of 4 species of copepod or, in 1 stomach, the euphausiid Meganyctiphanes norvegica. The largest multiple comprises 3 to 5 times the numbers of individuals that represent the second largest multiple and there is less difference in size of successively smaller multiples (see Table 10). The diversity within succes- 
Table 6. Recurrent prey species in the diets of the 35 more commonly caught species of demersal fish in the Rockall Trough. The numbers of predatory fish species and the numbers of bathymetric zones in which each prey is consumed are shown. There are 10 bathymetric zones at approximately $250 \mathrm{~m}$ intervals between 500 and $2900 \mathrm{~m}$ depth

\begin{tabular}{|c|c|c|}
\hline $\begin{array}{c}\text { Prey } \\
\text { species }\end{array}$ & $\begin{array}{c}\text { No. of } \\
\text { predatory } \\
\text { fish species }\end{array}$ & $\begin{array}{c}\text { No. of } \\
\text { bathymetric } \\
\text { zones }\end{array}$ \\
\hline \multicolumn{3}{|l|}{ Coelenterata } \\
\hline Anemones & 6 & 9 \\
\hline \multicolumn{3}{|l|}{ Copepoda } \\
\hline Calanus helgolandicus & 4 & 3 \\
\hline Aetideopsis multiserrata & 21 & 10 \\
\hline Euchaeta norvegica & 10 & 8 \\
\hline Xanthocalanus profundus & 6 & 6 \\
\hline Xanthocalanus spp. & 7 & 8 \\
\hline Pleuromamma spp. & 4 & 3 \\
\hline Heterorhabdus norvegicus & 5 & 4 \\
\hline \multicolumn{3}{|l|}{ Amphipoda } \\
\hline Ampellisca spp. & 8 & 5 \\
\hline Erichthonius spp. & 3 & 2 \\
\hline Lanceola spp. & 5 & 7 \\
\hline \multicolumn{3}{|l|}{ Mysidacea } \\
\hline Gnathophausia zoea & 9 & 10 \\
\hline Boreomysis arctica & 10 & 7 \\
\hline Boreomysis tridens & 11 & 6 \\
\hline Dactylerythrops gracilura & 4 & 6 \\
\hline Pseudomma affine & 10 & 5 \\
\hline Michthyops parva & 4 & 5 \\
\hline Amblyopsoides ohlinii & 5 & 5 \\
\hline Paramblyops bidigitata & 2 & 4 \\
\hline Paramblyops rostrata & 5 & 5 \\
\hline \multicolumn{3}{|l|}{ Euphausiacea } \\
\hline Meganyctiphanes norvegica & 18 & 6 \\
\hline \multicolumn{3}{|l|}{ Decapoda } \\
\hline Acanthephyra pelagica & 6 & 7 \\
\hline Pandalina brevirostris & 7 & 3 \\
\hline Pandalus propinquus & 4 & 3 \\
\hline Sergestes arcticus & 15 & 10 \\
\hline Pasiphaea tarda & 13 & 9 \\
\hline Crangonidae & 13 & 5 \\
\hline Munida bamffica & 13 & 6 \\
\hline Ophiuroidea & 10 & 7 \\
\hline
\end{tabular}

sively smaller multiples increases (Table 7), as would be expected.

The largest and second-largest multiples in fish with 4 and 3 co-occurring multiples are analysed in Table 8. The commonest 4 species comprising the largest multiples in both groups of fish are the same, and in the same order of dominance, as in fish with 5 or more multiples. The seasonal occurrence of these organisms among the stomach contents is shown in Table 9. Aetideopsis multiserrata and Heterorhabdus norvegicus are consumed throughout the year. The other 4 species are eaten more commonly at certain seasons
Table 7 Coryphaenoides rupestris. Prey species present as multiple incidences in the 43 stomachs with 5 or more cooccurring multiples (See Table 10). Only the 5 largest multiples are considered in stomachs with 6 or more. The prey species are ranked from the commonest to the rarest within each successively smaller multiple. The largest multiples in the 43 stomachs represented only 5 prey species while the second largest (Multiple 2) represented only 9 species

\begin{tabular}{|lrrrrr|} 
& \multicolumn{9}{c}{ Successively } & \multicolumn{3}{c|}{} \\
& 1 & 2 & 3 & 4 & 5 \\
& 1 & 1 & 3 & 4 & 9 \\
\hline Euchaeta norvegica & 2 & 6 & 3 & 3 & 2 \\
Pleuromamma robusta & 3 & 4 & 2 & 2 & 4 \\
Aetideopsis multiserrata & 4 & 2 & 8 & 7 & 4 \\
Calanus helgolandicus & 5 & 7 & 10 & 10 & \\
Meganyctiphanes norvegica & 5 & 5 & 6 & 6 \\
Pasiphaea tarda & & 3 & 1 & 1 & 1 \\
Heterorhabdus norvegicus & & 5 & 6 & 10 & \\
Gnathophausia zoea & & 7 & 6 & & \\
Boreomysis tridens & & 7 & 8 & 3 \\
Ostracods & & & 6 & 5 & 9 \\
Munida bamffica & & & & 9 & 8 \\
Sergestes arcticus & & & & & 6 \\
Scaphocalanus sp. & & & & & 8 \\
Euchirella curticauda & & & & & 9 \\
Undeuchaeta plumosa & & & & & 9 \\
Gaetanus kruppi & & & & & \\
\hline
\end{tabular}

but overlap each other. No seasonal pattern in the occurrence of multiple incidences among the stomach contents was detected.

\section{Evidence of exploitation of patches}

Possible evidence of exploitation of patches should occur in the 17 species where more than $50 \%$ of the total prey occur in stomachs with multiple incidences and where relatively large numbers of stomachs ( $>$ $100)$ have been examined. There are 7 species in this category (Tables $2 \& 3$ ). Multiple incidences occur singly in stomachs of Apristurus sp., as can be deduced from Table 2 by summing the number of different sized multiples and comparing with the number of stomachs that contain multiples (16 and 16); this species will be discussed later. Nezumia aequalis and Coryphaenoides guentheri are excluded because their diets contain more than $38 \%$ of items as unidentified copepods and amphipods (Mauchline \& Gordon 1984a); many of these organisms occur as multiples but, since they were not consistently identified to species in all stomachs, the data on these species are incomplete. The remaining 4 species are analysed in Table 10 along with Lepidion eques in which $46 \%$ of the total prey occur in stomachs with multiples but in which 303 with food were examined.

The stomachs of the different species of fish have been grouped according to the number of co-occurring 
Table 8. Coryphaenoides rupestris. Prey species present as multiple incidences in the 42 stomachs with 4 multiples and the 64 stomachs with 3 multiples (Table 10). The prey species are ranked from the commonest to the rarest within the largest (1) and second largest (2) multiple within both groups of fish

\begin{tabular}{|lrrrr|}
\hline & \multicolumn{2}{c}{ Fish with } & \multicolumn{2}{c|}{ Fish with } \\
& 4 multiples & 3 multiples \\
& 1 & 2 & 1 & 2 \\
\hline Euchaeta norvegica & 1 & 1 & 1 & 2 \\
Pleuromamma robusta & 2 & 3 & 2 & 3 \\
Aetideopsis multiserrata & 3 & 2 & 3 & 1 \\
Calanus helgolandicus & 4 & 3 & 4 & 3 \\
Heterorhabdus norvegicus & 5 & 6 & 5 & 6 \\
Meganyctiphanes norvegicus & 6 & & 6 & 6 \\
Isopods & 6 & & 8 & \\
Oikopleura sp. & 6 & & 10 & 3 \\
Pasiphaea tarda & & 3 & 7 & 10 \\
Scolecithrix sp. & & 6 & & \\
Undeuchaeta plumosa & & 6 & & \\
Gnathophausia zoea & & 6 & & \\
Ampellisca sp. & & & 9 & 6 \\
Ostracods & & & & 6 \\
Euchirella curticauda & & & & \\
\hline
\end{tabular}

envelope and there are close similarities between the results in Table 10 and the hypothetical situation described in Fig. 1 and Table 1.

Aspects of this concept of the stomach contents as an expanding envelope can be quantified by examining values of $m$ (Table 11), the slope of the regression line, for some of the correlations in Table 4 . The regression equation of Correlation 1 (Table 4 ) indicates than an additional multiple is obtained by the fish with every 6 to 20 items consumed. In Correlation 2, 5.3 to 10 of еvегу 10 items consumed contribute to multiple incidences, the balance ( $m$ values of regressions for CorreIation 3) contributing to the single items in the stomachs. Two additional correlations are significant but only within the stomach contents of Coryphaenoides rupestris and Nematonurus armatus. The number of items occurring as singles per stomach is correlated with the number of multiple incidences per stomach: values of $r$ are $0.457(\mathrm{p}<0.001)(m=$ $2.00)$ and $0.524(\mathrm{p}<0.001)(m=2.23)$ respectively. Thus 2 single items occur along with every multiple incidence. This regularity is reflected in a significant

Table 9. Coryphaenoides rupestris. Seasonal occurrence of the commonest prey organisms in multiple incidences expressed as the numbers per 100 stomachs with food in the 750 and $1000 \mathrm{~m}$ bathymetric zones

\begin{tabular}{|c|c|c|c|c|c|c|c|c|c|c|c|c|}
\hline & \multicolumn{2}{|c|}{$\begin{array}{l}\text { Euchaeta } \\
\text { norvegica }\end{array}$} & \multicolumn{2}{|c|}{$\begin{array}{l}\text { Pleuromamma } \\
\text { robusta }\end{array}$} & \multicolumn{2}{|c|}{$\begin{array}{l}\text { Aetideopsis } \\
\text { multiserrata }\end{array}$} & \multicolumn{2}{|c|}{$\begin{array}{c}\text { Calanus } \\
\text { helgolandicus }\end{array}$} & \multicolumn{2}{|c|}{$\begin{array}{l}\text { Heterorhabdus } \\
\text { norvegicus }\end{array}$} & \multicolumn{2}{|c|}{$\begin{array}{c}\text { Meganyctiphanes } \\
\text { norvegica }\end{array}$} \\
\hline & 750 & 1000 & 750 & 1000 & 750 & 1000 & 750 & 1000 & 750 & 1000 & 750 & 1000 \\
\hline Mar & 41 & 28 & 8 & 1 & 269 & 178 & 0 & 1 & 36 & 32 & 36 & 0 \\
\hline May & 101 & 35 & 24 & 3 & 147 & 93 & 0 & 1 & 67 & 28 & 2 & 0 \\
\hline Jul & 1671 & 286 & 84 & 26 & 106 & 129 & 88 & 147 & 101 & 37 & 3 & 0 \\
\hline Sep & 83 & 42 & 107 & 40 & 123 & 84 & 32 & 32 & 26 & 11 & 178 & 16 \\
\hline Nov & 78 & 15 & 259 & 1175 & 70 & 154 & 0 & 5 & 24 & 28 & 64 & 4 \\
\hline
\end{tabular}

multiple incidences of prey that each contains (Table 10). The numbers of items per multiple are not distributed normally about a mean because smaller numbers of organisms are more likely to comprise a multiple than large numbers. Stomachs of Coelorhynchus coelorhynchus with 1 multiple present have a mean number of items per multiple of 5.3 but the commonest multiple consists of 2 representatives of a species (Table 10). Stomachs with 2 multiples have one commonly of 3 and a second of 2 individuals. Stomachs with 3 multiples have the largest commonly with 5 organisms, the second largest with 3 or 4 and the smallest with 2 organisms. Similar analyses are given for stomachs of Coryphaenoides rupestris and Nematonurus armatus. Relatively few stomachs of Lepidion eques and Epigonus telescopus have more than 1 multiple and so they have been grouped into those with 1 and more than 1 multiple, and only the largest multiple is considered.

The stomach contents are like an expanding correlation between the number of items occurring as singles in the stomach and the number of items occurring as multiples: values of $r$ are $0.302(\mathrm{p}<0.001)(m=$ $0.09)$ and $0.293(p<0.05)(m=0.24)$ respectively. Thus 0.9 to 2.4 items occur as singles along with every 10 items occurring as multiples.

\section{FORAGING STRATEGIES}

There is, therefore, a considerable amount of structure within the stomach contents of species that must reflect foraging strategies, and even ontogenetic changes in strategies within species.

The quality and extent of the data on the following species do not allow conclusions on strategy to be drawn:

List 1. Centroscymnus crepidater

Nezumia aequalis

Malacocephalus laevis 
Table 10. Size of successively smaller multiple incidences of prey species in stomachs which have 2 to 6 co-occurring multiples. The modal number (with mean number in parenthesis) of organisms are given in each class of multiple. The numbers of stomachs with different numbers of co-occurring multiples are also given. Only the mean size of the largest multiple is given in stomachs of Lepidion eques and Epigonus telescopus where 2 or more multiples occur

\begin{tabular}{|c|c|c|c|c|c|c|c|}
\hline \multirow{2}{*}{$\begin{array}{l}\text { No. of co-occurring } \\
\text { multiples per stomach }\end{array}$} & \multirow{2}{*}{$\begin{array}{c}\text { No. of } \\
\text { stomachs }\end{array}$} & \multicolumn{6}{|c|}{ Successively smaller multiples } \\
\hline & & 1 & 2 & 3 & 4 & 5 & 6 \\
\hline \multicolumn{8}{|l|}{ Coelorhynchus coelorhynchus } \\
\hline 1 & 39 & $2(5.3)$ & & & & & \\
\hline 2 & 21 & $3(7.1)$ & $2(3.3)$ & & & & \\
\hline 3 & 5 & $5(5.0)$ & $3-4(3.2)$ & $2(2.2)$ & & & \\
\hline 4 & 4 & $8(8.0)$ & $5(5.3)$ & $4(4.0)$ & $2(3.3)$ & & \\
\hline \multicolumn{8}{|l|}{ Coryphaenoides rupestris } \\
\hline 1 & 228 & $2(5.2)$ & & & & & \\
\hline 2 & 134 & $3(11.9)$ & $2(3.1)$ & & & & \\
\hline 3 & 64 & $4(12.4)$ & $2(3.4)$ & $2(2.4)$ & & & \\
\hline 4 & 42 & $7-8(21.2)$ & $4(5.4)$ & $2(3.2)$ & $2(2.3)$ & & \\
\hline 5 & 29 & $13(179)$ & $5(6.6)$ & $4(4.1)$ & $2(3.0)$ & $2(2.1)$ & \\
\hline $6-10$ & 14 & $46(46.4)$ & $5(8.3)$ & $3-4(4.8)$ & $2(3.3)$ & $2(2.3)$ & $2(2.0)$ \\
\hline \multicolumn{8}{|l|}{ Nematonurus armatus } \\
\hline 1 & 25 & $2(4.4)$ & & & & & \\
\hline 2 & 12 & $3(3.7)$ & $2(2.5)$ & & & & \\
\hline 3 & 6 & $3-6(6.8)$ & $3(3.3)$ & $2(2.5)$ & & & \\
\hline \multicolumn{8}{|l|}{ Lepidion eques } \\
\hline 1 & 40 & $2(2.9)$ & & & & & \\
\hline$>1$ & 7 & $3(4.9)$ & & & & & \\
\hline \multicolumn{8}{|l|}{ Epigonus telescopus } \\
\hline 1 & 100 & $2(3.0)$ & & & & & \\
\hline$>1$ & 12 & $3(3.8)$ & & & & & \\
\hline
\end{tabular}

Table 11. Values for the slope, $m$, of the regression lines of various correlations detailed in Table 4

\begin{tabular}{|lccc|}
\hline & \multicolumn{4}{c|}{ Correlation no. } \\
& 1 & 2 & 3 \\
\hline Trachyrhynchus murrayi & 0.09 & 0.53 & 0.47 \\
Coelorhynchus coelorhynchus & 0.08 & 0.88 & 0.12 \\
Coelorhynchus occa & 0.03 & 1.00 & \\
Coryphaenoides rupestris & 0.04 & 0.86 & 0.14 \\
Nematonurus armatus & 0.09 & 0.58 & 0.42 \\
Phycis blennoides & 0.09 & 0.95 & \\
Lepidion eques & 0.08 & 0.68 & 0.32 \\
Epigonus telescopus & 0.05 & 0.70 & 0.30 \\
Lepidorhombus boscij & 0.18 & 0.81 & \\
Glyptocephalus cynoglossus & 0.06 & 0.91 & \\
\hline
\end{tabular}

\section{Coryphaenoides guentheri \\ Chalinura brevibarbis \\ Chalinura leptolepis \\ Chalinura mediterranea \\ Lionurus carapinus}

Stomachs of Centroscymnus crepidator, additional to the 12 listed in Table 2, were examined in bulk (Mauchline \& Gordon 1983a); 62 of the 75 stomachs contained 1 to 11 myctophid fish, not identified to species but probably representing multiple incidences in several instances. Some $60 \%$ of the stomach con- tents of Malacocephalus laevis are unidentified parts of fish while more than $35 \%$ of the contents of stomachs of the remaining macrourid fish in List 1 are unidentified copepods and amphipods (Mauchline \& Gordon 1984a) containing many, but undefined, instances of multiple incidences.

The rest of the 33 species in Table 2 can be ascribed to several categories on the basis of structure within their stomach contents.

The following list of species are those in which only 2 to $13 \%$ of stomachs contain multiple incidences, representing less than $16 \%$ of the total dietary items (Tables 2 \& 3).

List 2. Deania calcea

$$
\begin{aligned}
& \text { Etmopterus spinax } \\
& \text { Hydrolagus mirabilis } \\
& \text { Alepocephalus bairdii } \\
& \text { Xenodermichthys copei } \\
& \text { Argentina silus } \\
& \text { Synaphobranchus kaupi } \\
& \text { Polyacanthonotus rissoanus } \\
& \text { Gadiculus argenteus thori } \\
& \text { Helicolenus dactylopterus }
\end{aligned}
$$

Individual dietary items in these fishes tend to be large in size relative to the stomach capacity. The mean numbers of items per stomach range from 1.3 to 2.7 (Mauchline \& Gordon 1985). The percentage of 
total dietary items that occur in stomachs with multiples is 3 to $27 \%$ (Table 2). Consequently, the vast majority of stomach contents in these fish consist of a few single items of individual prey species. Foraging strategy is probably opportunistic to obtain prey of suitable size and handling characteristics.

The remaining species in Table 2 all have a greater occurrence of multiple incidences of prey in their stomachs. The following list comprises species where only 1 multiple incidence occurs in the stomach and if 2 or more do occur their occurrence is not related to the total number of items in the stomach (Correlation 1 in Table 4 is not significant):

List 3. Apristurus sp.

Chimaera monstrosa

Notacanthus bonapartei

Halargyreus johnsonii

Hoplostethus atlanticus

The mean numbers of items per stomach in these fishes range from 2.3 to 9.9 (Mauchline \& Gordon 1985). The first 3 species rarely have more than 1 multiple incidence per stomach. They are selective feeders in that Apristurus sp. feeds repetitively on Sergestes arcticus, Chimaera monstrosa on anemones, and Notacanthus bonapartei on brittle stars. The size of the multiple incidence is related to the total number of iterns in the stomach but the number of co-occurring single items shows a corresponding increase only in $C$. monstrosa (Table 4). This suggests that Apristurus sp. and $N$. bonapartei lock on to their preferred prey species while $C$. monstrosa does not. Larger $C$. monstrosa and $N$. bonapartei eat more prey (Table 4), and so more of their preferred species, than smaller individuals. This is not true of Apristurus sp. Stomachs of these 3 species with multiples contain more than $60 \%$ of total dietary items (Table 3 ) implying that the preferred prey and associated organisms are their primary diet. Opportunistic foraging, as described for species in List 2, also takes place but to a lesser degree.

The other 2 species Halargyreus johnsonii and Hoplostethus atlanticus have 87 and $70 \%$ respectively of the total dietary items contained in stomachs with multiples (Table 3). Multiple incidences in stomachs of $H$. johnsonii are usually of the copepod Euchaeta norvegica, as many as 39 occurring in a single stomach (Mauchline \& Gordon 1984b). This implies a high degree of repetitive feeding and to the possible exclusion of other species since single items do not show similar increases in number (Table 4). Single items do increase in number as the total number of items in the stomach of $H$. atlanticus and so are consumed along with the preferred prey species.

Consequently, foraging in species in List 3 consists of exploitation of a preferred prey species, even to the partial exclusion of feeding on other dietary items.
A further 4 species in Tables 2 and 3 have a dietary structure similar to species in List 3 except that repetitive feeding takes place on a number of preferred prey species. The fish are:

List 4. Coelorhynchus occa

Phycis blennoides

Lepidorhombus boscii

Glyptocephalus cynoglossus

The number of single items does not increase as the total number of items in the stomach and so repetitive feeding on preferred prey seems to be to the exclusion of random foraging. The vast bulk of prey recorded in the stomachs of Coelorhynchus occa and Phycis blennoides occurred in stomachs with multiples whereas lesser proportions were found in comparable stomachs of the other 2 species (Table 3). These latter 2 species are flatfish whose ranges extend from the shelf to upper slope of the Rockall Trough. Larger $P$. blennoides have fewer items per stomach than smaller individuals (Table 4) because they tend to feed on larger individuals of the same prey species as preferred by the smaller fish. No such relation exists in the diets of the other 3 species.

The remaining species in Table 2 exploit a wide variety of preferred prey repetitively. They are:

List 5. Trachyrhyncus murrayi

Coelorhynchus coelorhynchus

Coryphaenoides rupestris

Nematonurus armatus

Lepidion eques

Epigonus telescopus

This list should also probably include the macrourids Nezumia aequalis, Coryphaenoides guentheri, Chalinura brevibarbis and C. mediterranea from List 1 but further data on them is required for confirmation.

Lepidion eques and Epigonus telescopus had only about half the total dietary items in stomachs with multiple incidences compared with more than $70 \%$ in the other 4 species (Table 3). The principal prey are decapod crustaceans in $L$. eques and decapods, mysids and fish in E. telescopus (see Mauchline \& Gordon $1980,1984 \mathrm{c}$ ). These are, on average, larger prey than consumed by the other species (macrourids) on this list and account for the higher incidences of single items among the stomach contents. Larger E. telescopus eat fewer but larger items (Table 4) but no such relation existed in the diet of $L$. eques. A considerable amount of opportunistic foraging for single suitable prey of larger size must take place in these 2 species.

Prey size in the macrourids is restricted within a much narrower size spectrum. Most prey are small relative to the size of the fish (Mauchline \& Gordon 1984 a). Only 14 to $28 \%$ of dietary items occurred in stomachs of fish that had been feeding exclusively on single prey (Table 3), a large proportion of these 
stomachs being less than half full. Multiples and the singles associated with them are very important in the diets of these species and opportunistic foraging for single items is probably at a minimum in these species.

\section{CONCLUSIONS}

The comparative composition of the contents of individual stomachs of demersal fish from the slope of the Rockall Trough between depths of 400 and $2900 \mathrm{~m}$ appear to contain information not exploited during conventional dietary analyses. A large proportion of the species feed primarily on benthopelagic fauna. Those that exploit the epibenthic environment feed primarily on amphipods, brittle stars and anemones. Infaunal elements of the benthos are almost entirely absent from the stomach contents. Diets of some species are diverse while those of others are relatively specialised (Mauchline \& Gordon 1985). The particle size of prey items of macrourid fish in particular is small and the contents of individual stomachs can consist of 150 to 200 items. Feeding on patches of prey seems logical, especially as many of the species dominant in stomach contents (Table 6) are known or suspected to aggregate.

Small particle size of prey is very true of Coryphaenoides rupestris in considering the 4 species of copepods representing the 4 commonest multiples in the diet (Tables $7 \& 8$ ). It is not true, however, of multiples of the euphausiid Meganyctiphanes norvegica which is a significantly larger type of prey. In general, however, the largest multiples are of smaller prey simply because stomachs are restricted in capacity. There are exceptions and so availability of prey has some influence inferred, for example, from the occurrence of $82 M$. norvegica along with a further $6 \mathrm{co}$ occurring multiples ranging from 2 to 7 individuals of 5 species of copepods and an ostracod in a single stomach of C. rupestris; or of 11 myctophid fish, probably of the same species, in a stomach of Centroscymnus crepidater. These 2 examples suggest that exploitation of aggregations or shoals of prey organisms takes place. It is generally accepted that the majority of pelagic prey species occur in patches (Angel 1977, Horwood \& Cushing 1978), and Rex (1981) reviews evidence of patchiness in the distribution of benthic organisms.

Assuming that fish exploit aggregations and that multiple incidences of prey species in stomachs are a direct reflection of this, then several questions arise. For instance, why does a fish not simply fill its stomach with 1 preferred species at a time? This was not recorded once among 5500 stomachs with food examined in the 33 species discussed here. Thus exclu- sive feeding on a single prey species is avoided. This is even true of species in List 3 which only repetitively feed on 1 preferred prey species but always have single items present along with multiples.

There is certainly evidence in species in Lists 3 and 4 of locking-on to preferred prey species but this does not totally exclude but rather decreases the proportion of single items in the stomachs. A different interpretation of locking-on would be exploitation of singlespecies as opposed to multi-species patches. This might account for the occasional single items included. The particular species that might be exploiting singlespecies patches are Apristurus sp., Chimaera monstrosa, Notacanthus bonapartei, Coelorhynchus occa, Phycis blennoides and Halargyreus johnsonii.

The progressive situation in Table 11 describing the structure of diets of species in List 5 is closely similar to the hypothetical situation in Fig. 1 and Table 2, derived from the data of Haury \& Wiebe (1982). It would appear to explain the observed structure within these stomach contents by suggesting that the fish are exploiting multispecies patches. Data on the microstructure within patches are lacking but individual species are more likely to occur in aggregations within the patches rather than be randomly distributed throughout. In addition, a patch may also contain organisms that the species of fish, for one reason or another, may not select; such species are not included in Fig. 1. The converse is also true, namely that one or more species within a multispecies patch may be especially selected by the fish. Neither of these aspects can be resolved in the absence of representative samples of the multispecies patches on which the fish are hypothetically feeding.

Foraging strategies of species in Lists 2 to 5 can be interpreted as showing a progressive development. Species in List 2 are primarily opportunistic feeders that occasionally obtain multiples of a prey species on a haphazard basis. Species in List 3 are also opportunistic feeders but lock on to a preferred single prey species that they exploit fairly regularly on a repetitive basis. Species in List 4 are similar to those in List 3 but exploit several preferred prey species and may or may not lock on to them. Species in List 5 have the most diverse diets and combine opportunistic and repetitive feeding much more closely, suggesting that they may be exploiting multi-species patches on a regular basis.

Acknowledgements. We would like to thank Dr. R. N. Gibson for constructive criticism of the manuscript. The Dunstaffnage Marine Research Laboratory is financed by the Natural Environment Research Council. 


\section{LITERATURE CITED}

Alldredge, A. L., Robinson, B. H., Fleminger, A., Torres, J. J., King, J. M., Hamner, W. M. (1984). Direct sampling and in situ observation of a persistent copepod aggregation in the mesopelagic zone of the Santa Barbara Basin. Mar Biol. 80: 75-81

Angel, M. V (1977). Windows into a sea of confusion: sampling limitations to the measurement of ecological parameters in oceanic mid-water environments. In: Andersen, N. R., Zahuranec, B. J. (ed.) Oceanic sound scattering prediction. Marine Science Vol. 5. Plenum Press, New York and London, p. 217-248

Geistdoerfer, P. (1973). Regime alimentaire de Macrouridae (Téleostéens, Gadiformes) atlantiques et mediterranéens en relation avec la morphologie du tube digestif. Bull. Mus. Hist. nat., Paris, Ser. 3 (161) Ecol. gen. 17: 285-295

Geistdoerfer, P. (1978). Ecologie alimentaire des Macrouridae. Rev. Trav. Inst. Pêches maritime 42: 173-261

Gordon, J. D. M., Duncan, J. A. R. (1985). The ecology of the deep-sea benthic and benthopelagic fish on the slopes of the Rockall Trough, northeastern Atlantic. Prog. Oceanogr. 15: 37-69

Haury, L. R., Wiebe, P. H. (1982). Fine-scale multi-species aggregations of oceanic zooplankton. Deep Sea Res. 29 A: 915-921

Haury, L. R., McGowan, J. A., Wiebe, P. H. (1978). Patterns and processes in the time-scales of plankton distributions. In: Steele, J. H. (ed.) Spatial pattern in plankton communities. Plenum Press, New York and London, p. $277-327$

Holme, N. A., McIntyre, A. D. (eds) (1984). Methods for the study of marine benthos. Blackwell Scientific Publications, Oxford

Horwood, J. W., Cushing, D. H. (1978). Spatial distribution and ecology of pelagic fish. In: Steele, J. H. (ed.) Spatial pattern in plankton communities. Plenum Press, New York and London, p. 355-383

Hureau, J. C., Monod, Th. (ed.) (1979). Check-Iist of the fishes of the north-eastern Atlantic and of the Mediterranean. UNESCO, Paris, Parts 1 and 2
McLellan, T (1977). Feeding strategies of the macrourids. Deep Sea Res. 24: 1019-1036

Marshail, N. B (1965). Systematic and biological studies of the macrourid fishes (Anacanthini-Teleostei). Deep Sea Res. 12: 299-322

Marshall, N. B., Merrett, N. R. (1977). The existence of a benthopelagic fauna in the deep sea. Deep Sea Res. (Suppl.) 483-497

Mauchline, J., Gordon, J. D. M. (1980). The food and feeding of the deep-sea morid fish Lepidion eques (Günther 1887) in the Rockall Trough. J. mar, biol. Ass. U. K. 60: 1053-1059

Mauchline, J., Gordon, J. D. M. (1983a). Diets of the sharks and chimaeroids of the Rockall Trough, northeastern Atlantic Ocean. Mar. Biol. 75: 269-278

Mauchline, J., Gordon, J. D. M. (1983b). Diets of clupeoid, stomiatoid and salmonoid fish of the Rockall Trough, northeastern Atlantic Ocean. Mar. Biol. 77: 67-78

Mauchline, J., Gordon, J. D. M. (1984a). Diets and bathymetric distributions of the macrouid fish of the Rockall Trough, northeastern Atlantic Ocean. Mar. Biol. 81: $107-121$

Mauchline, J., Gordon, J. D. M. (1984b). Feeding and bathymetric distribution of the gadoid and morid fish of the Rockall Trough. J mar. biol. ass. U.K. 64: 657-665

Mauchline, J., Gordon, J. D. M. (1984c). Occurrence and feeding of berycomorphid and percomorphid teleost fish in the Rockall Trough. J. Cons. int. Explor Mer. 41: 239-247

Mauchline, J., Gordon, J. D. M. (1985). Trophic diversity in deep-sea fish. J. Fish Biol. 26: 527-535

Okamura, O. (1970). Studies of the macrourid fishes of Japan - morphology, ecology and phylogeny. Rep. Usa mar. biol. Stn Kochi Univ. 17: 1-179

Rex, M. A. (1981). Community structure in the deep-sea benthos. Ann. Rev. Ecol. Syst. 12: 331-353

Steele, J. H. (ed.) (1978). Spatial pattern in plankton communities. Plenum Press, New York and London 